\title{
Non Communicable Disease (NCD) as Risk for Disability: Recommendation for Indonesian UHC Program
}

\author{
Siti Isfandari ${ }^{1}$, Lamria Pangaribuan ${ }^{1} \&$ Sri Idaiani ${ }^{1}$ \\ ${ }^{1}$ National Institute of Health Research and Development, Indonesia Ministry of Health \\ Correspondence: Siti Isfandari, National Institute of Health Research and Development, jl Percetakan Negara 29, \\ Jakarta 10560, Tel: 62-21-424-4693. E-mail: isfandari.riskesdas@gmail.com
}

Received: February 26, 2020 Accepted: March 21, 2020 Online Published: June 12, 2020

doi:10.5539/gjhs.v12n8p118

URL: https://doi.org/10.5539/gjhs.v12n8p118

\begin{abstract}
Background: Disability is health condition drives people seek treatment. Information on magnitude of disability and its contributors is important in Indonesian universal health coverage (UHC) era. It is useful for cost estimation, as well as to design type of service needed at the time being and in the future. This research intends to assess magnitude of disability and its non-communicable diseases (NCD) as risk. Disability obtained from WHODAS 2 score.

Method: data obtained from 2018 National Health Survey (Riskesdas 2018) sample age 18 - 59, consisted of 528762 respondents. Dependent variable is disability measured using WHODAS2. Independent variables are NCD consist of statements ever diagnosed asthma, cancer, diabetes, heart, stroke, chronic renal failure, and joint disease by healthcare personnel and emotional distress which is score obtained from self-report questionnaire (SRQ) instrument.

Statistic Analysis: Validation between disability and 2 diseases was performed using Chi Square analysis. Logistic regression analysis was applied to identify contribution of NCD on disability.

Results: Results show risk of NCD on disability in the working age group of 18-59 years. Stroke and emotional distress are the highest contributors with OR more than 3. Results can serve as input for UHC program to estimate costs of working age health service, including rehabilitation. The Ministry of Health can develop or improve current health system with comprehensive services provision including psychological intervention in rehabilitation.
\end{abstract}

Keywords: disability, Indonesia, JKN, NCD, UHC

\section{Introduction}

Disability is health condition makes a person seek treatment (Üstün, Kostanjsek, Chatterji, \& Rehm, 2010). People with disabilities due to NCD may need long-term physical, mental, intellectual and sensory services (Richards et al., 2016). Identification of disability attributors could assist the needs for resource allocation for healthcare and social welfare expenditures (Chi et al., 2001). Policies for reducing disability caused by chronic disorders embrace disease prevention strategies, rehabilitation and support focused on function recovery, compensatory measures and comprehensive care management (Rodríguez-Blázquez et al., 2016). Priorities should be targeted to function domains with higher impact on activity limitations and participation restrictions (ALRP) (Rodríguez-Blázquez et al., 2016).

Disability is common with increasing age, and is associated with physical morbidity (Harwood et al., 1998), depression (Wells et al., 1989; Lyness et al., 1993; Alexopoulos et al., 1996), and cognitive impairment (Mehta et al., 2002). Accurate and comprehensive disability measurement is an important requirement for evaluating interventions mostly in later life (Kim et al., 2005). Measuring disability is important in disease burden and the effectiveness of health intervention evaluation, level of functioning as well as health needs monitoring in a population, designing service provision and assessing equal opportunity (Cheung et al., 2015). Increasing need for social services, e.g. healthcare, and a loss in quality of life is associated with disability. It is crucial for strategies development to reduce the burden of disability to enable the future health care system to cope with increasing demands, and to avoid strong decrements in the quality of life. Identifying diseases with highest contribution to disability, and clarifying whether large contributions are related with high prevalence of disease or with high 
disabling impact, i.e. a high extent the disease leads to disability is one of the first crucial steps in strategies development. (Klijs, Nusselder, Looman, \& Mackenbach, 2011).

In Indonesian UHC era, information on magnitude of disability and its disease contributor is valuable to estimate cost and type of service needed. Information on NCD and disability obtained through health survey provides strong base; Includes costs and treatment estimation. Research aims to assess magnitude of disability as well as contribution of NCD as high cost chronic and catastrophic disease. Result is for cost estimation and preparing types of healthcare services and programs for people with disabilities. It can provide inputs for MOH to prepare preventive, promotion and treatment program. Disability data has been collected by National Institute of Health Research and Development (NIHRD) through several public health surveys SKRT, followed by Riskesdas 2007, 2013 and 2018.

\section{Methodology}

Information on disability and NCD were obtained from Riskesdas 2018, cross sectional Indonesian population health survey with PPS (probability proportional to size) sampling system representing up to district level estimation (National Institute Of Health Research And Development MOH Indonesia, 2018). Disability score obtained from WHODAS2 (Üstün, Kostanjsek, Chatterji, \& Rehm, 2010), while NCD was statement ever diagnosed asthma, cancer, diabetes, heart, stroke, chronic renal failure, and joint disease by healthcare personnel. Emotional distress is score obtained from self-report questionnaire (SRQ) instrument, developed by WHO. Emotional distress defined as having SRQ score at least 6 (Beusenberg \& Orley, 1994; Idaiani Sri, 2012).

WHODAS2, instrument for disability measurement, was developed by WHO based on ICF concept assessing limitation or disruption of functions (Üstün, Kostanjsek, Chatterji, \& Rehm, 2010). WHODAS2 short version consists of 12 statements was applied. Prior to carrying out core analysis, cut off score calculation was performed. The cut off score are as follows $0=$ no disability, $1-25=$ mild, 25.00001-48.99 = moderate and 48.99800146-100= severe. This is similar with (Ida et al., 2017). To simplify interpretation, the groups were divided into 2 categories: no disability consists of no until mild and with disability consist of moderate until severe (Table 1).

Univariate, bivariate and multivariate logistic regression using SPSS version 15 was applied to perform statistical analysis.

\section{Results}

Table 1. Proportion of respondents with disability, Riskesdas 2018

\begin{tabular}{ll}
\hline Disability category & $\%(\mathrm{~N}=528762)$ \\
\hline No difficulty & 60,8 \\
Mild difficulty & 28,2 \\
Moderate difficulty & 9,5 \\
Severe difficulty & 1,2 \\
No - mild difficulty & 89,0 \\
Moderate - severe difficuoty & 10,7 \\
\hline
\end{tabular}

The image shows higher category of disability has less proportion of respondents. Regrouping into 2 categories is for more simple interpretation. Moderate group is put into severe for estimation and anticipation.

\subsection{Validation of Disability by Age and 2 NCDs: Asthma and Diabetes.}

Results is displayed in Tables 2 and 3.

The image shows as age increases, the proportion without disabilities decreases. While the proportion of disabilities at all levels increase with age. It shows disability data obtained using WHODAS2 is good. (Table 2) 
Table 2. Proportion of disability level by age

\begin{tabular}{llllll}
\hline \multirow{2}{*}{ Disability category } & \multicolumn{2}{l}{ Age } & & $\mathrm{N}$ \\
\cline { 2 - 6 } & $18-29$ & $30-39$ & $40-49$ & $50-59$ & $(527444)$ \\
\cline { 2 - 6 } & $(140775)$ & $(141379)$ & $(139904)$ & $(105386)$ & 61,0 \\
\hline No difficulty & 64,5 & 63,5 & 60,5 & 53,5 & 28,3 \\
\hline Mild difficulty & 26,5 & 27,0 & 28,7 & 31,9 & 9,6 \\
\hline Moderate & 8,3 & 8,7 & 9,6 & 12,2 & 1,2 \\
\hline Severe & 0,7 & 0,8 & 1,1 & 2,4 & 89,3 \\
\hline No - mild & 91,0 & 90,5 & 89,3 & 14,3 & 10,7 \\
\hline Moderate - severe & 9,0 & 9,5 & 10,7 & 14,7 & 89,3 \\
\hline
\end{tabular}

Similar patterns remain after grouping into 2 categories.

Validation with NCD (table 3)

Table 3. Proportion of disability level by Asthma and Diabetes

\begin{tabular}{|c|c|c|c|c|c|c|}
\hline \multirow[b]{2}{*}{ Disability Category } & \multicolumn{2}{|l|}{ Asthma } & \multirow{2}{*}{$\begin{array}{l}\mathrm{N} \\
527444\end{array}$} & \multicolumn{2}{|c|}{ Diabetes } & \multirow{2}{*}{$\begin{array}{l}\mathrm{N} \\
527444\end{array}$} \\
\hline & $\begin{array}{l}\text { Yes } \\
(12551)\end{array}$ & $\begin{array}{l}\text { No } \\
\text { (514893) }\end{array}$ & & $\begin{array}{l}\text { Yes } \\
(9034)\end{array}$ & $\begin{array}{l}\text { No } \\
\text { (518410) }\end{array}$ & \\
\hline No difficulty & 47,2 & 61,3 & 60,97 & 43,8 & 61,3 & 60,97 \\
\hline Mild & 37,0 & 28,1 & 28,3 & 37,0 & 28,1 & 28,3 \\
\hline Moderate & 12,9 & 9,5 & 9,6 & 15,0 & 9,5 & 9,6 \\
\hline Severe & 2,9 & 1,1 & 1,2 & 4,3 & 1,1 & 1,2 \\
\hline
\end{tabular}

Both images show group with asthma or diabetes diagnosis have higher proportion of disability. Proportion of no difficulty is higher in group without asthma or diabetes diagnosis. Face validity methods shows disability data is good.

\subsection{Logistic Regression Analysis}

Table 4 shows major NCD contribution to disability. Without emotional distress disorder, stroke is the highest contributor. Addition of emotional distress reduces strength of stroke. Emotional Distress and stroke become the highest risk for moderate - severe disability. In addition to stroke and emotional distress, all the NCD are risks of disability. The lowest contributors are asthma and joint diseases. Women, older age and living in rural area increase risk of disability. Addition of emotional distress reduces female risk to disability, but not place of living and older age. Since incidence of disability more often occurs in senior age groups, selection of ages 40 years or older is performed (Table 4).

There is not much difference of almost NCD contribution to disability with age selection of 40 and older, although slight increase in several diseases. However, in some extent, grouping of residence changes contribution of NCD on disability. Contribution of asthma and cancer to disability is less stable in urban people. Some urban areas show no significant contribution of asthma and cancer to of disability. It could be due to distinct variation of asthma and cancer treatment, some urban areas perform or have better system on those diseases management. Stroke is the highest contributor of disability in urban areas.

NCD, disability and UHC (Table 5) 
Table 4. Major NCD and emotional distress contributions to moderate - severe disability all ages

\begin{tabular}{|c|c|c|c|c|c|c|c|c|}
\hline \multicolumn{9}{|l|}{ Categorical Variable Information } \\
\hline & $\begin{array}{l}\mathrm{N} \\
\text { (Weighted) }\end{array}$ & $\begin{array}{l}\% \\
\text { Weighted }\end{array}$ & \multicolumn{3}{|c|}{$\begin{array}{l}\text { Without emotional stress } \\
\text { disorder }\end{array}$} & \multicolumn{2}{|c|}{$\begin{array}{l}\text { With emotional } \\
\text { disorder }\end{array}$} & stress \\
\hline No-mild disability & 480832,9776 & 91,2 & \multicolumn{3}{|l|}{$95 \% \mathrm{CI}$} & \multicolumn{3}{|c|}{$95 \% \mathrm{CI}$} \\
\hline \multirow[t]{2}{*}{ Moderate - severe disability } & 46591,44515 & 8,8 & & & & & & \\
\hline & & & $\begin{array}{l}\text { Odds } \\
\text { Ratio }\end{array}$ & Lower & Upper & $\begin{array}{l}\text { Odds } \\
\text { Ratio }\end{array}$ & Lower & Upper \\
\hline Ever diagnosed asthma & 12650,82724 & 2,4 & 1,4 & 1,3 & 1,5 & 1,2 & 1,1 & 1,3 \\
\hline Ever diagnosed cancer & 1184,002937 & 0,2 & 1,7 & 1,4 & 2,1 & 1,5 & 1,2 & 1,8 \\
\hline Ever diagnosed diabetes & 8601,640359 & 1,6 & 1,6 & 1,5 & 1,8 & 1,5 & 1,3 & 1,6 \\
\hline Ever diagnosed heart diseases & 7773,609992 & 1,5 & 1,6 & 1,4 & 1,7 & 1,4 & 1,3 & 1,5 \\
\hline Ever diagnosed stroke & 3108,959147 & 0,6 & 3,8 & 3,4 & 4,2 & 3,3 & 2,9 & 3,7 \\
\hline $\begin{array}{l}\text { Ever diagnosed renal failure chronic } \\
\text { disease at least } 3 \text { months consequently }\end{array}$ & 1775,941804 & 0,3 & 1,7 & 1,4 & 2,1 & 1,4 & 1,1 & 1,6 \\
\hline Ever diagnosed rheumatic / joint disease & 32769,22565 & 6,2 & 1,5 & 1,4 & 1,6 & 1,3 & 1,3 & 1,4 \\
\hline emotional distress & 49169,24594 & 9,3 & & & & 3,5 & 3,4 & 3,7 \\
\hline Female & 259632,4779 & 49,2 & 1,2 & 1,2 & 1,2 & 1,1 & 1,1 & 1,1 \\
\hline $18-29$ & 168248,9326 & 31,9 & 1 & 1 & 1 & 1 & 1 & 1 \\
\hline $30-39$ & 138589,3747 & 26,3 & 1,0 & 0,9 & 1,0 & 1,0 & 0,9 & 1,0 \\
\hline $40-49$ & 125915,3542 & 23,9 & 1,1 & 1,0 & 1,1 & 1,1 & 1,0 & 1,1 \\
\hline $50-59$ & 94670,76124 & 17,9 & 1,5 & 1,4 & 1,5 & 1,5 & 1,5 & 1,6 \\
\hline Rural & 230829,661 & 43,8 & 1,5 & 1,4 & 1,6 & 1,5 & 1,4 & 1,6 \\
\hline Population Size & 527424,4227 & 100,0 & & & & & & \\
\hline
\end{tabular}


Table 5. Major NCD and emotional distress contributions to moderate - severe disability age 40 - 59

\begin{tabular}{|c|c|c|c|c|c|c|c|c|c|c|c|c|c|c|c|}
\hline & & & & & $\begin{array}{l}\text { Age } \\
40++\end{array}$ & & & & & $\begin{array}{l}40++ \\
\text { urban }\end{array}$ & & & & & $\begin{array}{l}40++ \\
\text { rural }\end{array}$ \\
\hline & $\mathrm{N}$ & $\%$ & & & & $\mathrm{~N}$ & $\%$ & & & & $\mathrm{~N}$ & $\%$ & & & \\
\hline Categorical Variable Information & Weighted & Weighted & & & & Weighted & Weighted & & & & Weighted & Weighted & & & \\
\hline No - mild disability & 197550,7 & 89,6 & & & & 110854,8 & 91,3 & & & & 86695,9 & 87,4 & & & \\
\hline Moderate - severe disability & 23035,45 & 10,4 & OR & lo & up & 10552,8 & 8,7 & OR & lo & up & 12482,7 & 12,6 & OR & lo & up \\
\hline Ever diagnosed asthma & 5821,32 & 2,6 & 1,3 & 1,1 & 1,4 & 3374,5 & 2,8 & 1,0 & 0,8 & 1,2 & 2446,9 & 2,5 & 1,5 & 1,4 & 1,7 \\
\hline Ever diagnosed cancer & 779,1104 & 0,4 & 1,5 & 1,1 & 1,9 & 509,8 & 0,4 & 1,4 & 0,9 & 2,0 & 269,3 & 0,3 & 1,6 & 1,2 & 2,3 \\
\hline Ever diagnosed diabetes & 7755,782 & 3,5 & 1,4 & 1,3 & 1,5 & 5233,6 & 4,3 & 1,4 & 1,2 & 1,6 & 2522,2 & 2,5 & 1,4 & 1,3 & 1,6 \\
\hline Ever diagnosed heart disease & 5202,728 & 2,4 & 1,3 & 1,2 & 1,4 & 3232,9 & 2,7 & 1,3 & 1,1 & 1,5 & 1969,8 & 2,0 & 1,3 & 1,1 & 1,5 \\
\hline Ever diagnosed stroke & 2702,541 & 1,2 & 3,5 & 3,1 & 3,9 & 1768,2 & 1,5 & 3,5 & 3,0 & 4,2 & 934,3 & 0,9 & 3,4 & 2,9 & 4,0 \\
\hline $\begin{array}{l}\text { Ever diagnosed chronic renal failure (at leaset } 3 \\
\text { consecutive months ) }\end{array}$ & 1148,388 & 0,5 & 1,4 & 1,2 & 1,7 & 600,3 & 0,5 & 1,7 & 1,2 & 2,3 & 548,1 & 0,6 & 1,2 & 0,9 & 1,5 \\
\hline Ever diagnosed joint diseases / trheumatic & 23335,87 & 10,6 & 1,3 & 1,2 & 1,4 & 12322,0 & 10,1 & 1,3 & 1,2 & 1,5 & 11013,9 & 11,1 & 1,3 & 1,2 & 1,4 \\
\hline Emotional distress & 21657,94 & 9,8 & 3,6 & 3,4 & 3,8 & 11165,8 & 9,2 & 3,6 & 3,3 & 3,9 & 10492,2 & 10,6 & 3,6 & 3,4 & 3,8 \\
\hline Female & 110728,9 & 50,2 & 1,2 & 1,1 & 1,2 & 60869,9 & 50,1 & 1,2 & 1,1 & 1,3 & 49859,0 & 50,3 & 1,2 & 1,1 & 1,2 \\
\hline $40-49$ & 125915,4 & 57,1 & 1 & 1 & 1 & 69811,4 & 57,5 & 1 & 1 & 1 & 56104,0 & 56,6 & 1 & 1 & 1 \\
\hline $50-59$ & 94670,76 & 42,9 & 1,4 & 1,4 & 1,5 & 51596,2 & 42,5 & 1,4 & 1,4 & 1,5 & 43074,5 & 43,4 & 1,4 & 1,3 & 1,4 \\
\hline Rural & 99178,54 & 45,0 & 1,5 & 1,4 & 1,6 & 121407,6 & 100,0 & & & & 99178,5 & 100,0 & & & \\
\hline Population Size & 220586,1 & 100,0 & & & & & & & & & & & & & \\
\hline
\end{tabular}


Table 6. Prevalence of NCD and proportion of their moderate to severe disability

\begin{tabular}{|c|c|c|c|c|c|c|}
\hline & Prevalence & $\begin{array}{l}95 \% \\
\text { Interval }\end{array}$ & Confidence & $\begin{array}{l}\text { Proportio } \\
\mathrm{n}\end{array}$ & $\begin{array}{l}95 \% \\
\text { Interval }\end{array}$ & Confidence \\
\hline & & Lower & Upper & & Lower & Upper \\
\hline Diagnosed Asthma & 2,4 & 2,3 & 2,4 & 12,7 & 12,1 & 13,2 \\
\hline Diagnosed cancer & 0,2 & 0,2 & 0,2 & 16,6 & 14,7 & 18,2 \\
\hline Diagnosed DM & 1,6 & 1,6 & 1,7 & 17,3 & 16,5 & 17,9 \\
\hline Diagnosed heart disease & 1,5 & 1,4 & 1,5 & 16,0 & 15,3 & 0,25 \\
\hline Diagnosed stroke & 0,6 & 0,6 & 0,6 & 32,1 & 30,8 & 33,3 \\
\hline $\begin{array}{l}\text { Diagnosed renal failure } 3 \text { consecutive } \\
\text { months }\end{array}$ & 0,3 & 0,3 & 0,4 & 17,7 & 16,0 & 19,2 \\
\hline Diagnosed RA & 6,2 & 6,1 & 6,3 & 14,5 & 14,1 & 14,9 \\
\hline Emotional distress & 9,3 & 9,2 & 9,4 & 23,2 & 22,9 & 23,5 \\
\hline
\end{tabular}

The figure in Table 6 shows prevalence of NCD and their moderate to severe disabilities proportion in $18-59$ age groups. Prevalence of stroke as the highest contributor to disability, in addition to emotional distress, is quite low, but a little more than $30 \%$ is experiencing moderate-severe disabilities. While the prevalence of emotional distress as strongest contributor of moderate to severe disability is the highest. The image implies it is important for UHC to allocate budget for psychological emotional therapy in patients with NCD, as well as provision of rehabilitative services in NCD patients due to moderate to severe disability they may experience.

\section{Discussion}

Result of Riskesdas 2018 data analysis show NCD contribution to disability in working age group 18-59 years. It is in line with (Le, Dorstyn, Mpfou, Prior, \& Tully, 2018; Alonso et al., 2004) that arthritis, chronic lung and heart diseases affect physical functions deterioration. It is demonstrated with higher scores of SF-36. Research in Impact of chronic illness on quality of life in 8 countries shared similar results (Alonso et al., 2004). Study in Spain among non-clinical population identify strong association of health conditions and body function ; impairments for: dementia with mental functions, cerebrovascular disease with neuro - musculoskeletal function, and chronic renal failure (Rodríguez-Blázquez et al., 2016). Dutch study on contribution of chronic disease to disability identified the disabling impact of selected chronic diseases. Musculoskeletal and cardiovascular disease contributed most to the burden of disability, but chronic nonspecific lung disease among males and diabetes among females also contributed much. Arthritis and heart disease were less disabling but contributed substantially because of their high prevalence (Klijs et al., 2011).

First phase of analysis identifies major NCD contribution which result shows population group with stroke having 4 times higher risk of experiencing moderate - severe disability than group without stroke. It is in line with the study (Yokota et al., 2015). WHODAS II scale and subscales as disability instrument showed generally satisfactory validity for stroke patients and their relatives as proxies. It differentiates fully function patients and perceived recovered from stroke patients and those who felt independent differed considerably and significantly from the respective others in all sub- and total scores (Schlote et al., 2009).

Addition of emotional distress variable changes the risk of stroke to the disability. It reduced to 3.5 times. Stroke and emotional distress are still the highest contributors. Depression is predictor of physical function quality deterioration in CHD patients. Identification of depression in CHD patients can help treatment of CHD patients who are at risk of experiencing physical functioning. Depression management can improve physical function of CHD patients (Dickens, Cherrington, \& McGowan, 2012). Having lower score of depression predicts lower disability score of all domains (MoMoen, Drageset, Eide, \& Gjesdal, 2018). Association of physical illness, depression, and cognitive functions with disability measured by the WHODAS II, is supported by (Kim et al., 2005) study.

Selection of $40-59$ years age group leads to slight change of NCD and emotional distress contribution on disability. Stroke and emotional distress are still the highest contributors. Age selection increases contribution of emotional distress. All age and age selection shows arthritis as the most stable contributor to disability in addition to stroke and emotional distress. This is in line with (Alonso et al., 2004) that Arthritis as highest contributor of 
HRQL highest score in 8 countries. Although we used different instrument, (Garin et al., 2010) showed WHODAS2 as valid tool to measure disability based on ICF model. (Schlote et al., 2009)(Küçükdeveci et al., 2013)(Huang et al., 2018)(Federici, Bracalenti, Meloni, \& Luciano, 2017)

Analysis based on domicile improves the model. Modeling in rural areas is better than that of urban. There is different risk contribution of NCD to moderate - severe disability between urban and rural populations. But emotional distress and stroke remain as the greatest contributor. Asthma shows unstable contributions, ranging from not contributing to become risk of moderate - severe disability in urban model. It can be interpreted treatment of asthma in urban areas is vary, some good and other still need improvement. Whereas model in rural areas shows contribution of chronic renal failure is insignificant / unstable. This phenomenon needs to be explored. Results of analysis from Riskesdas 2018 data show NCD contribution and emotional distress to moderate - severe disability. Selection by age and place of residence further emphasize the contribution. Asthma, cancer and chronic renal failure require further exploration due to their unstable contribution to moderate-severe disability in urban and rural areas.

The analysis can provide overview of moderate - severe disability in Indonesian population with NCD for MOH and its stakeholders to design and provide health service for the working age group (Gulley et al., 2018). With increasing Indonesian life expectancy, analyses can be utilized for early detection and prevention of disability. European and USA countries experiences can be modeled. Although there is higher prevalence of NCD due to increase life expectancy, prevalence of disability remains stable. This is due to the success of early detection and treatment programs, to disability prevention (Hung, Ross, Boockvar, \& Siu, 2012) (Hung, Ross, Boockvar, \& Siu, 2011).

Information from this analysis can be used as input for health care model development according to the needs of working age group with NCD and disability. Ministry of Health has developed Adult Integrated Health Service known as Posbindu, monthly program measuring blood pressure and blood sugar as screening and early detection of NCD for those age 60 or higher. Results of this analysis can be used as input for Posbindu program to be expanded for working age group. It also can be used for UHC program to estimate cost of service by taking into account the prevalence of NCD and disability management. Emotional distress management program developed by professional psychiatrists, psychologists and nurses contributes to disability reduction for productive age population with NCD and could save cost of healthcare services.

Limitations: there are two limitations. Firstly is disability level greatly depends on severity level of the disease. However the survey did not include the diseases severity level. It may weaken association of disability with the NCD. Second limitation is disability is a fairly complicated phenomenon to measure. Riskesdas 2018 was using WHODAS2. Extracting information using WHODAS2 requires an interviewer and respondent understanding. There is a possibility of interpretation differences affecting answers and disability scores. But the validation of the disability score using cut off point indicates the instrument WHODAS2 Riskesdas 2018 quite good. No severity level of the disease may lead to different contribution on disability compared with other studies.

\section{Competing Interests Statement}

The authors declare that there are no competing or potential conflicts of interest.

\section{References}

Alonso, J., Ferrer, M., Gandek, B., Ware, J. E., Aaronson, N. K., Mosconi, P., ... Leplège, A. (2004, March). Health-related quality of life associated with chronic conditions in eight countries: Results from the International Quality of Life Assessment (IQOLA) Project. Quality of Life Research, 13, 283-298. https://doi.org/10.1023/B:QURE.0000018472.46236.05

Cheung, M. K. T., Hung, A. T. F., Poon, P. K. K., Fong, D. Y. T., Li, L. S. W., Chow, E. S. L., ... Liou, T. H. (2015). Validation of the World Health Organization Assessment Schedule II Chinese Traditional Version (WHODAS II CT) in persons with disabilities and chronic illnesses for Chinese population. Disability and Rehabilitation, 37(20), 1902-1907. https://doi.org/10.3109/09638288.2014.989336

Chi, W.-C., Chang, K.-H., Escorpizo, R., Yen, C.-F., Liao, H.-F., Chang, F.-H., ... Liou, T.-H. (2001). Measuring Disability and Its Predicting Factors in a Large Database in Taiwan Using the World Health Organization Disability Assessment Schedule 2.0. Int. J. Environ. Res. Public Health, 11, 11. https://doi.org/10.3390/ijerph111212148

Dickens, C., Cherrington, A., \& McGowan, L. (2012). Depression and health-related quality of life in people with coronary heart disease: A systematic review. European Journal of Cardiovascular Nursing, 11(3), 265-275. 
https://doi.org/10.1177/1474515111430928

Federici, S., Bracalenti, M., Meloni, F., \& Luciano, J. V. (2017, November 6). World Health Organization disability assessment schedule 2.0: An international systematic review. Disability and Rehabilitation, 39, 2347-2380. https://doi.org/10.1080/09638288.2016.1223177

Garin, O., Luis Ayuso-Mateos, J., Almansa, J., Nieto, M., Chatterji, S., Vilagut, G., ... Ferrer, M. (2010). Open Access RESEARCH Validation of the "World Health Organization Disability Assessment Schedule, WHODAS-2" in patients with chronic diseases. In Health and Quality of Life Outcomes (Vol. 8). https://doi.org/10.1186/1477-7525-8-51

Gulley, S. P., Rasch, E. K., Bethell, C. D., Carle, A. C., Druss, B. G., Houtrow, A. J., .. Chan, L. (2018, April 1). At the intersection of chronic disease, disability and health services research: A scoping literature review. Disability and Health Journal, 11, 192-203. https://doi.org/10.1016/j.dhjo.2017.12.012

Huang, S. W., Chi, W. C., Chang, K. H., Yen, C. F., Liao, H. F., Escorpizo, R., \& Liou, T. H. (2018). World health organization disability assessment schedule 2.0 as an objective assessment tool for predicting return to work $\begin{array}{llll}\text { after a stroke. Disability and Rehabilitation, 40(21), 2592-2597. } & \text {. }\end{array}$ https://doi.org/10.1080/09638288.2017.1342280

Hung, W. W., Ross, J. S., Boockvar, K. S., \& Siu, A. L. (2011). Recent trends in chronic disease, impairment and disability among older adults in the United States. BMC Geriatrics, 11. https://doi.org/10.1186/1471-2318-11-47

Hung, W. W., Ross, J. S., Boockvar, K. S., \& Siu, A. L. (2012). Association of chronic diseases and impairments with disability in older adults: A decade of change? Medical Care, 50(6), 501-507. https://doi.org/10.1097/MLR.0b013e318245a0e0

Ida, M., Naito, Y., Tanaka, Y., Matsunari, Y., Inoue, S., \& Kawaguchi, M. (2017). Feasibility, reliability, and validity of the Japanese version of the 12-item World Health Organization Disability Assessment Schedule-2 in preoperative patients. Journal of Anesthesia, 31(4), 539-544. https://doi.org/10.1007/s00540-017-2349-8

Idaiani Sri, \& Basuki Bastaman. (2012). Postpartum depression in Indonesia women: a national study. Health Science Journal Indonesia, 3(1), 3-8. Retrieved from http://ejournal.litbang.depkes.go.id/index.php/HSJI /article/view/396/97

Kim, J.-M., Stewart, R., Glozier, N., Prince, M., Kim, S.-W., Yang, S.-J., ... Yoon, J.-S. (2005). Physical health, depression and cognitive function as correlates of disability in an older Korean population. International Journal of Geriatric Psychiatry, 20(2), 160-167. https://doi.org/10.1002/gps.1266

Klijs, B., Nusselder, W. J., Looman, C. W., \& Mackenbach, J. P. (2011). Contribution of chronic disease to the burden of disability. PLOS ONE, 6(9). https://doi.org/10.1371/journal.pone.0025325

Küçükdeveci, A. A., Kutlay, Ş., Yildizlar, D., Öztuna, D., Elhan, A. H., \& Tennant, A. (2013). The reliability and validity of the World Health Organization Disability Assessment Schedule (WHODAS-II) in stroke. Disability and Rehabilitation, 35(5), 214-220. https://doi.org/10.3109/09638288.2012.690817

Le, J., Dorstyn, D. S., Mpfou, E., Prior, E., \& Tully, P. J. (2018, October 1). Health-related quality of life in coronary heart disease: a systematic review and meta-analysis mapped against the International Classification of Functioning, Disability and Health. Quality of Life Research, 27, 2491-2503. https://doi.org/10.1007/s11136-018-1885-5

Beusenberg, M., \& Orley, J. (1994). A users guide to the self report questionnaire (SRQ). WHO.

MoMoen, V. P., Drageset, J., Eide, G. E., \& Gjesdal, S. (2018). Dimensions and predictors of disability-A baseline study of patients entering somatic rehabilitation in secondary care. PLoS ONE, 13(3). https://doi.org/10.1371/journal.pone.0193761en

Drageset, J., Eide, G. E., \& Gjesdal, S. (2018). Dimensions and predictors of disability-A baseline study of patients entering somatic rehabilitation in secondary care. PLoS ONE, 13(3). https://doi.org/10.1371/journal.pone.0193761

National Institute Of Health Research And Development MOH Indonesia. (2018). Laporan Riskesdas 2018. Retrieved https://labdata.litbang.depkes.go.id/riset-badan-litbangkes/menu-riskesnas/menu-riskesdas/426-rkd-2018 
Richards, N. C., Gouda, H. N., Durham, J., Rampatige, R., Rodney, A., \& Whittaker, M. (2016, March 1). Disability, noncommunicable disease and health information. Bulletin of the World Health Organization, 94, 230-332. https://doi.org/10.2471/BLT.15.156869

Rodríguez-Blázquez, C., Damián, J., Andrés-Prado, M. J., Almazán-Isla, J., Alcalde-Cabero, E., Forjaz, M. J., ... De Pedro-Cuesta, J. (2016). Associations between chronic conditions, body functions, activity limitations and participation restrictions: A cross-sectional approach in Spanish non-clinical populations. BMJ Open, 6(6). https://doi.org/10.1136/bmjopen-2015-010446

Schlote, A., Richter, M., Wunderlich, M. T., Poppendick, U., Mller, C., Schwelm, K., \& Wallesch, C. W. (2009). WHODAS II with people after stroke and their relatives. Disability and Rehabilitation, 31(11), 855-864. https://doi.org/10.1080/09638280802355262

Üstün, T. B., Kostanjsek, N., Chatterji, S., \& Rehm, J. (2010). Measuring Health and Disability: Manual for WHO Disability Assessment Schedule WHODAS 2.0. World Health Organization, 90. Retrieved from https://doi.org/10.2471/BLT.09.067231

Yokota, R. T. C., Berger, N., Nusselder, W. J., Robine, J. M., Tafforeau, J., Deboosere, P., \& Van Oyen, H. (2015, December 12). Contribution of chronic diseases to the disability burden in a population 15 years and older, Belgium, 1997-2008. BMC Public Health, 15. https://doi.org/10.1186/s12889-015-1574-z

\section{Copyrights}

Copyright for this article is retained by the author(s), with first publication rights granted to the journal.

This is an open-access article distributed under the terms and conditions of the Creative Commons Attribution license (http://creativecommons.org/licenses/by/4.0/). 